\title{
The Role of Complement in Experimental Bullous Pemphigoid
}

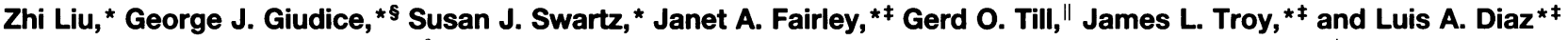 \\ Departments of $*$ Dermatology and ${ }^{\S}$ Biochemistry, Medical College of Wisconsin, Milwaukee, Wisconsin $53226 ;{ }^{\ddagger}$ Veterans Affairs \\ Medical Center, Milwaukee, Wisconsin 53295; and "Department of Pathology, University of Michigan Medical School, \\ Ann Arbor, Michigan 48109
}

\begin{abstract}
Bullous pemphigoid (BP) is a blistering skin disease associated with an IgG autoimmune response directed against the ectodomain of the hemidesmosomal protein, BP180. An animal model of BP has recently been developed by our laboratory based on the passive transfer of rabbit antimurine BP180 antibodies into neonatal BALB/c mice. The experimental animals develop a blistering disease that reproduces all of the key immunopathological features of BP. In the present study we have investigated the role of complement in the pathogenesis of subepidermal blistering in the mouse model of BP. We demonstrate the following. ( $a$ ) Rabbit anti-murine-BP180 IgG was effective in inducing cutaneous blisters in a C5-sufficient mouse strain, but failed to induce disease in the syngeneic C5-deficient strain; $(b)$ neonatal BALB/c mice, pretreated with cobra venom factor to deplete complement, became resistant to the pathogenic effects of the anti-BP180 IgG; (c) F( $\left.\mathbf{a b}^{\prime}\right)_{2}$ fragments generated from the anti-BP180 IgG exhibited no pathogenic activity in the mouse model; and $(d)$ histologic evaluation of the skin of mice described in points $b$ and $c$ above showed minimal or no neutrophilic cell infiltration in the upper dermis. Thus, anti-BP180 antibodies trigger subepidermal blistering in this BP model via complement activation. This experimental model of BP should greatly facilitate future studies on the pathophysiology of autoantibody-mediated diseases of the dermal-epidermal junction. (J. Clin. Invest. 1995. 95:1539-1544.) Key words: autoimmunity - hemidesmosome $\bullet$ skin $\cdot$ basement membrane $\cdot$ mouse model
\end{abstract}

\section{Introduction}

Bullous pemphigoid (BP) ${ }^{1}$ is an acquired, subepidermal blistering disease of the elderly first described in 1953 by Lever (1). In BP patients basal keratinocytes of the epidermis detach from the underlying basement membrane producing tense, fluidfilled vesicles. Similar skin lesions were observed in a pregnancy-associated non-viral disorder, herpes gestationis (HG)

Address correspondence to Zhi Liu, Ph.D., Department of Dermatology, Medical College of Wisconsin, 8701 Watertown Plank Road, Milwaukee, WI 53226. Phone: 414-456-4087; FAX: 414-266-8673.

Received for publication 8 September 1994 and in revised form 28 November 1994.

1. Abbreviations used in this paper: BMZ, basement membrane zone; BP, bullous pemphigoid; CVF, cobra venom factor; GST, glutathione S-transferase; HG, herpes gestationis; IF, immunofluorescence.

The Journal of Clinical Investigation, Inc.

Volume 95, April 1995, 1539-1544
(2). Jordon et al. (3) demonstrated by immunofluorescence (IF) techniques that patients with BP exhibit circulating and tissue-bound autoantibodies directed against antigens of the cutaneous basement membrane zone (BMZ). HG patients were also shown to produce complement-fixing IgG autoantibodies that exhibit a linear BMZ staining pattern identical to that of BP autoantibodies (4-6).

Two independent antigen/antibody systems associated with BP and HG have recently been characterized at the molecular level (7-10). Both of these autoantigens, designated BP180 and BP230, have been localized to the epidermal hemidesmosome, an organelle that anchors basal keratinocytes to the dermis (10-12). The BP180 antigen is a $180-\mathrm{kD}$ transmembrane protein with a type II orientation (13), i.e., the amino-terminal domain localizes to the intracellular hemidesmosomal plaque (14), while the carboxy-terminal half, made up of a long collagenous tail, projects into the extracellular milieu of the $\mathrm{BMZ}$ (15-17).

A recent epitope mapping study revealed that BP and HG autoantibodies recognize a common antigenic site within the major noncollagenous stretch of the BP180 ectodomain (17). This autoantibody-reactive site, designated MCW-1, has been mapped to a 14 amino acid stretch within the NC16A domain of this human antigen. The MCW-1 epitope, however, is absent from the murine BP180 protein $(17,18)$. The mouse system has been used successfully to test other pathogenic anti-epidermal autoantibodies (e.g., pemphigus) by passive transfer techniques $(19,20)$; however, the absence of the MCW-1 epitope from mouse skin precluded the use of this system for testing the pathogenicity of anti-BP180 autoantibodies present in human $\mathrm{BP}$ sera $(21,22)$. To circumvent this problem rabbit polyclonal antibodies were generated against the murine BP180 NC16A domain and were passively transferred into neonatal mice. Remarkably, the injected animals developed a subepidermal blistering disease that closely mimicked BP and HG (18). On histological examination lesional skin of these animals showed subepidermal vesicles and an intense neutrophilic infiltrate in the upper dermis. Direct IF of perilesional skin showed rabbit antibodies and murine $\mathrm{C} 3$ bound to the $\mathrm{BMZ}$ producing a linear pattern. Thus, it was concluded that binding of anti-BP180 antibodies to their target site in the cutaneous BMZ initiates a cascade of events that leads to subepidermal vesiculation.

The aim of the present investigation was to define the role of complement in subepidermal blistering observed in the mouse model of BP. We found that mice depleted of complement (either genetically or by pretreatment with cobra venom factor [CVF]) did not develop blistering disease following injection with pathogenic rabbit anti-BP180 antibodies. Additionally, $\mathrm{F}\left(\mathrm{ab}^{\prime}\right)_{2}$ fragments generated from this pathogenic rabbit IgG did not induce disease in injected animals. These results demonstrate that complement activation is an essential component in the pathogenesis of blister formation in the experimental model of BP. 


\section{Methods}

Laboratory animals. Breeding pairs of mice of the following strains BALB/c, B10-D2-OSN (C5-deficient strain), and B10-D2-NSN (C5sufficient strain) were purchased from The Jackson Laboratories (Bar Harbor, ME) and maintained at the Medical College of Wisconsin Animal Resource Center. Neonatal mice ( $24-36 \mathrm{~h}$ old with body weights between 1.4 and $1.8 \mathrm{~g}$ ) were used for passive transfer experiments.

Preparation of pathogenic rabbit anti-murine IgG. The preparation of recombinant murine BP180 and the immunization of rabbits were performed as previously described (18). Briefly, a segment of the murine BP180 antigen encompassing amino acids 495 to 643 of the ectodomain of this protein (using the numbering system of Li et al. [23]) was expressed as a glutathione $S$-transferase (GST) fusion protein using the pGEX prokaryotic expression system (Pharmacia LKB Biotechnology, Piscataway, NJ). The first 18 and final 86 residues of this 149-amino acid murine BP180 insert exhibited $89.4 \%$ identity when aligned with the human BP180 sequence; however, the remaining 45 amino acids (corresponding to residues 513 to 557 of murine BP180) showed significant divergence from the human sequence ( $37.8 \%$ identity). The murine BP180 fusion protein, designated GST-mus180A, was purified to homogeneity by affinity chromatography (24). New Zealand White rabbits were immunized with the purified murine BP180 fusion protein and the IgG fraction from the sera was purified as previously described (18). The IgG fractions were concentrated, sterilized by ultrafiltration and the protein concentrations determined by $\mathrm{OD}_{280}(\mathrm{E}[1 \%, 1 \mathrm{~cm}]$ $=13.6$ ). The titers of rabbit anti-murine BP180 antibodies in the rabbit sera and in the purified IgG fractions were assayed by indirect IF using mouse skin cryosections as substrate. These antibody preparations were also tested by immunoblotting for reactivity with the GST-mus180A fusion protein. The IF and immunoblotting techniques have been reported elsewhere (18).

Injection of $\mathrm{IgG}$ in C5-deficient and C5-sufficient mice. Neonates of the B10-D2-OSN (C5-deficient) and B10-D2-NSN (C5-sufficient) strains received two intraperitoneal (i.p.) injections ( $100 \mu \mathrm{l}$ each, five $\mathrm{h}$ apart) of a sterile solution of IgG in PBS (total dose: $5 \mathrm{mg} / \mathrm{g}$ body weight/day). Neonatal BALB/c mice were treated with the same injection schedule and were used as positive controls. The injection techniques have been described elsewhere $(18-20)$.

Depletion of complement by cobra venom factor and injection procedures. CVF was prepared as previously described (25). Three units of purified CVF in $100 \mu \mathrm{l}$ of PBS were injected i.p. into neonatal mice 12 $\mathrm{h}$ before the first IgG injection. The control group received only PBS. Both groups of animals received two $100 \mu \mathrm{l}$ i.p. injections of rabbit anti-murine BP180 IgG, (total dose: $5 \mathrm{mg} / \mathrm{g}$ body weight/day), 12 and $17 \mathrm{~h}$ after CVF treatment.

Preparation of $\mathrm{F}\left(a b^{\prime}\right)_{2}$ fragments and injection procedures. $\mathrm{F}\left(\mathrm{ab}^{\prime}\right)_{2}$ fragments of purified pathogenic and normal rabbit IgG fractions were prepared by digestion with pepsin (26). Undigested IgG and $\mathrm{Fc}$ fragments were removed by affinity chromatography using a staphylococcal protein A-Sepharose 4B column (Pharmacia Foe Chemicals, Piscataway, $\mathrm{NJ})$. The rabbit $\mathrm{F}\left(\mathrm{ab}^{\prime}\right)_{2}$ preparations showed a single precipitin line by double immunodiffusion with a goat anti-rabbit$\mathrm{F}\left(\mathrm{ab}^{\prime}\right)_{2}$ serum and was unreactive with a goat anti-rabbit-Fc serum (Cappel, Durham, NC). Unreduced SDS-PAGE of the $F\left(a b^{\prime}\right)_{2}$ fragments showed a band of $100 \mathrm{kD}$.

For injection procedures neonatal mice were divided into three groups and in all cases the $\operatorname{IgG}$ or $\mathrm{F}\left(\mathrm{ab}^{\prime}\right)_{2}$ was administered with two i.p. injections $(100 \mu \mathrm{l}$ each) given five hours apart. The first group (positive control) received intact anti-murine BP180 IgG (total dose: $5 \mathrm{mg} / \mathrm{g}$ body weight/day). The second group (test animals) received the $\mathrm{F}\left(\mathrm{ab}^{\prime}\right)_{2}$ fragment of anti-murine BP180 IgG (total dose: $4 \mathrm{mg} / \mathrm{g}$ body weight/day, which is roughly an equimolar dose compared with the intact IgG injections). The third group (negative control) received injections of $\mathrm{F}\left(\mathrm{ab}^{\prime}\right)_{2}$ generated from normal rabbit IgG (total dose: 4 $\mathrm{mg} / \mathrm{g}$ body weight/day).

Animal evaluation. The skin of neonatal mice from the test and control groups were examined $16 \mathrm{~h}$ after the last i.p. injection of the
IgG fractions. The extent of cutaneous disease was scored as follows: " (-)," no detectable skin disease; " $1+$," mild erythematous reaction with no evidence of the "epidermal detachment" sign (this sign was elicited by gentle friction of the mouse skin which, when positive, produced fine, persistent wrinkling of the epidermis); " $2+$, , intense erythema and "epidermal detachment" sign in localized areas; and " $3+$, ,' intense erythema with frank "epidermal detachment" sign involving $>20 \%$ of the epidermis. The skin disease in each group of animals was recorded by photography.

The animals were then sacrificed and the following specimens were obtained: lesional skin for light microscopy, perilesional skin for direct IF studies and mouse serum for indirect IF analysis. Direct and indirect IF analyses were performed as previously described $(19,20)$. Monospecific FITC-conjugated goat anti-rabbit IgG was obtained commercially (Kirkeggard \& Perry Laboratories Inc., Gaithersburg, MD). Goat antirabbit $\mathrm{F}\left(\mathrm{ab}^{\prime}\right)_{2}$, and monospecific goat anti-mouse $\mathrm{C} 3$ were purchased from Cappel Laboratories (Durham, NC). To map the antigenic sites on the blisters induced in neonatal mice, lesional biopsies were snapfrozen in liquid nitrogen and $4-\mu \mathrm{m}$ sections were prepared. These cryosections were incubated with a well-characterized human BP serum containing autoantibodies that recognize the BP230 antigen (intracellular hemidesmosomal plaque) and the BP180 antigen. IgG bound to the lesional mouse cryosection was visualized using FITC-conjugated goat antihuman IgG (Kirkeggard \& Perry Laboratories Inc., Gaithersburg, MD).

\section{Results}

C5-deficient mice injected with pathogenic $\operatorname{Ig} G$ do not develop disease. $16 \mathrm{~h}$ after i.p. injection of rabbit anti-murine BP180 IgG, all nine C5-sufficient (B10-D2-NSN) mice exhibited epidermal blistering. These lesions produced a positive "epidermal detachment" sign as shown in Fig. $1 A$ (also see Table I). By indirect IF, a human BP serum stained the epidermal side of these blisters, producing a staining pattern identical to that seen in lesions of BP patients. Direct IF of perilesional skin showed a linear staining of the BMZ with rabbit IgG (Fig. $1 B$ ), although the staining was variable and appeared to be site-dependent. Mouse C3 was also detected by direct IF along the BMZ of perilesional skin producing a linear staining pattern (Fig. $1 C$ ).

In contrast, none of the 12 C5-deficient (B10-D2-OSN) mice exhibited blisters 16 hours after injection with rabbit antimurine BP180 IgG. Fig. $1 D$ shows these results. Direct IF studies of the skin of these animals showed rabbit IgG and murine $\mathrm{C} 3$ bound to the $\mathrm{BMZ}$ of the injected mice (Fig. 1, $E$ and $F$ ). The sera of both groups of mice, (C5 deficient and C5 sufficient) showed circulating rabbit anti-BP180 antibodies at titers of $1: 1280$ or above.

Mice depleted of complement by CVF and injected with pathogenic IgG do not develop disease. In a preliminary series of experiments we showed that injection of neonatal BALB/c mice with $3 \mathrm{U}$ of $\mathrm{CVF}$ was sufficient to eliminate $\mathrm{C} 3$ from the circulation as demonstrated by double immunodiffusion using a goat anti-mouse C3 serum. Murine C3 remained absent from the serum for a period of $24 \mathrm{~h}$ after injection.

In eight of eight neonatal mice pre-treated with PBS (in place of CVF), the pathogenic rabbit anti-murine BP180 IgG produced extensive epidermal disease (Fig. $2 A$; Table I). These animals exhibited subepidermal blisters as determined by light microscopic examination, and showed linear deposition of rabbit IgG (Fig. $2 B$ ) and murine C3 (Fig. $2 C$ ) at the BMZ by direct IF analysis.

In contrast, none of the neonatal mice pre-treated with CVF and then injected i.p. with rabbit anti-murine BP180 IgG showed any clinical evidence of skin disease (n:8) (Fig. $2 D$ ). 


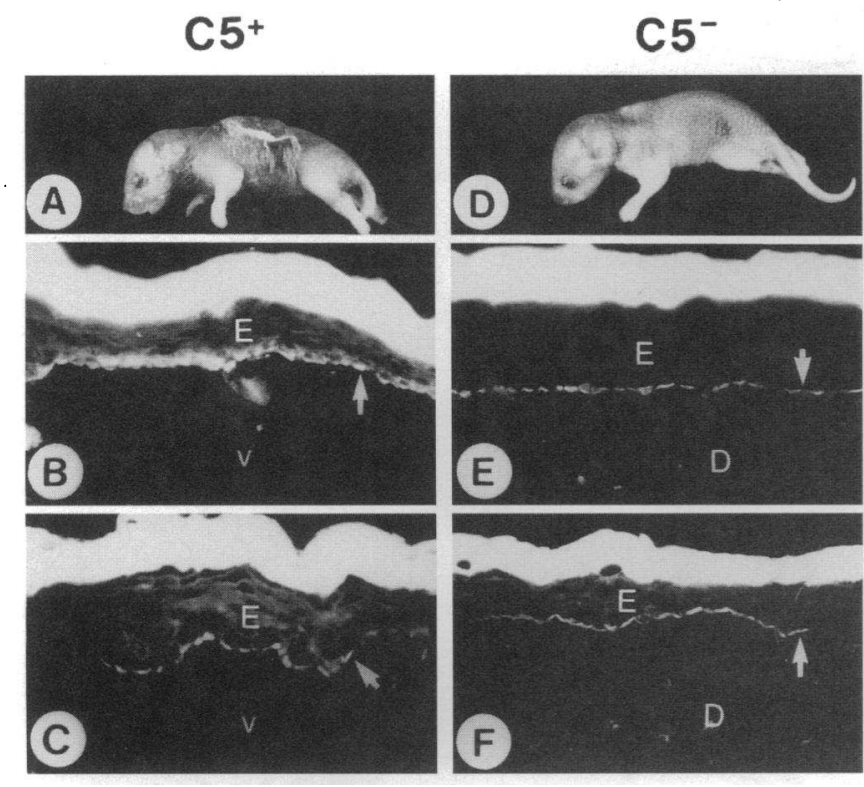

Figure 1. Clinical and immunofluorescence analysis of C5-deficient and C5-sufficient neonatal mice injected with rabbit anti-murine BP180 IgG. $16 \mathrm{~h}$ after i.p. injection of rabbit anti-murine BP180 IgG, C5-sufficient mice (strain B10-D2-NSN) exhibited the "epidermal detachment" sign (persistent subepidermal wrinkling produced by gentle friction) $(A)$. Direct IF analysis of lesional skin from the mouse shown in panel $\mathrm{A}$ demonstrated linear deposition of rabbit $\operatorname{IgG}(B)$ and $\mathrm{C} 3(C)$ along the cutaneous BMZ. The binding of the rabbit IgG was variable and appeared to be site-dependent. After treatment with rabbit anti-murine BP180 IgG, C5-deficient mice (strain B10-D2-OSN) did not exhibit any sign of blistering $(D)$. Direct IF studies of the skin of these C5deficient animals showed rabbit anti BP180 IgG $(E)$ and murine C3 [panel F] bound to the BMZ of the injected mice. Site of antibody labeling (arrow), dermis $(D)$, epidermis $(E)$, vesicle $(V)(\times 400)$.

The skin of these animals showed no evidence of subepidermal vesiculation at the light microscopic level. Direct IF studies showed rabbit IgG deposition at the BMZ (Fig. $2 E$ ), but an absence of murine $\mathrm{C} 3$ (Fig. $2 F$ ). The titers of rabbit antiBP180 IgG in the sera of both CVF-treated and PBS-treated animals were virtually the same $(>1,280)$ at the time of evaluation. Murine C3 levels, however, were undetectable only in animals pre-treated with CVF.

$F\left(a b^{\prime}\right)_{2}$ fragments from pathogenic rabbit IgG do not in-

Table I. Summary: The Role of Complement in BP Blister Formation

\begin{tabular}{llcc}
\hline \multicolumn{1}{c}{ Host mice } & $\begin{array}{c}\text { Immunoglobulin } \\
\text { injected }\end{array}$ & $\begin{array}{c}\text { Number } \\
\text { of mice }\end{array}$ & $\begin{array}{c}\text { Disease } \\
\text { activity* }\end{array}$ \\
\hline BALB/c & Intact IgG & 54 & $3+$ \\
Bio-D2-NSN (C5-sufficient) & Intact IgG & 9 & $3+$ \\
Bio-D2-OSN (C5-deficient) & Intact IgG & 12 & - \\
BALB/c (CVF-treated) & Intact IgG & 8 & - \\
BALB/c & $\mathrm{F}\left(\mathrm{ab}^{\prime}\right)_{2}$ & 5 & - \\
& & & \\
\hline
\end{tabular}

* Disease activity is scored on a scale of "-" to " $3+$." " -", means no detectable skin lesion; " $3+$ " means intense erythema with frank "epidermal detachment" sign involving $>20 \%$ of the epidermis.

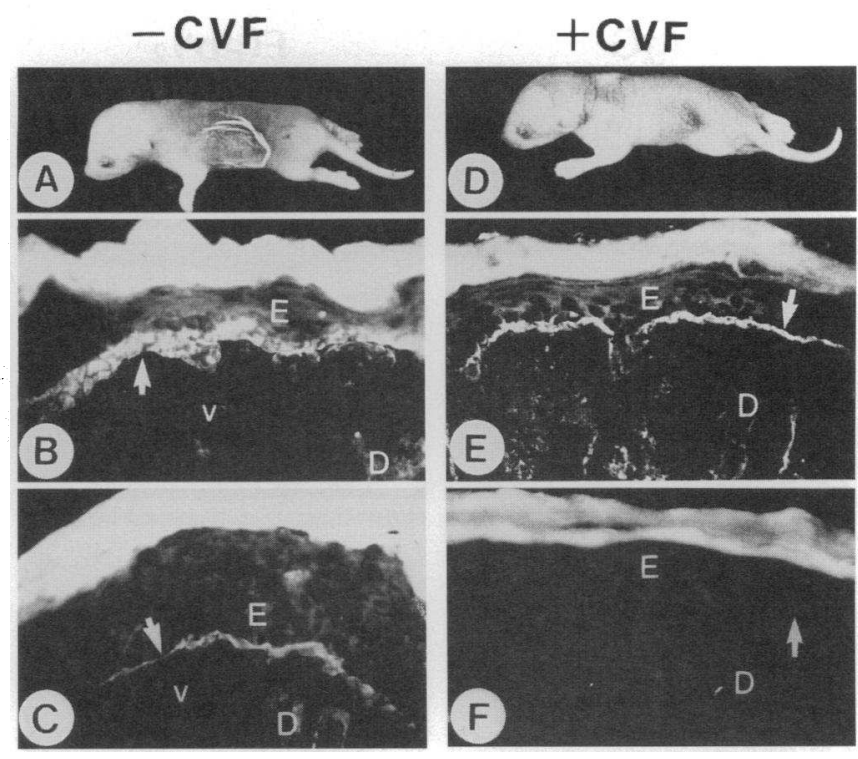

Figure 2. Clinical and immunofluorescence analysis of neonatal BALB/ c mice pretreated with cobra venom factor and injected with rabbit antimurine BP180 IgG. Pathogenic rabbit anti-murine BP180 IgG produced extensive epidermal disease in neonatal BALB/c mice pre-treated with PBS (in place of cobra venom factor [CVF]) $(A)$. The skin of these animals showed subepidermal blisters under light microscopic examination and linear deposition of rabbit $\operatorname{IgG}(B)$ and murine $\mathrm{C} 3(C)$ at the $\mathrm{BMZ}$ by direct IF. In contrast, neonatal $\mathrm{BALB} / \mathrm{c}$ mice pretreated with CVF and injected i.p. with rabbit anti-murine BP180 IgG showed no clinical evidence of skin disease $(D)$. These animals showed no evidence of subepidermal vesiculation at the light microscopic level. Direct IF studies showed rabbit IgG deposition at the $\mathrm{BMZ}(E)$ but absence of murine C3 $(F)$. Site of antibody labeling (arrow), dermis $(D)$, epidermis $(E)$, vesicle $(V)(\times 400)$.

duce disease. The control group of neonatal $\mathrm{BALB} / \mathrm{c}$ mice injected with intact rabbit anti-murine IgG developed extensive blisters (n:15) (Fig. $3 A$; Table I). These blisters were subepidermal as seen by light microscopy. Rabbit IgG and murine C3 were shown to be deposited along the $\mathrm{BMZ}$ of perilesional skin (Fig. 3, $B$ and $C$, respectively). In contrast, the skin of neonatal mice that received injections of $\mathrm{F}\left(\mathrm{ab}^{\prime}\right)_{2}$ (generated from the same rabbit anti-murine BP180 IgG) did not show evidence of blistering clinically (Fig. $3 \mathrm{D}$ ) or histologically. Pirect IF studies of the skin of these mice demonstrated that the rabbit $\mathrm{F}\left(\mathrm{ab}^{\prime}\right)_{2}$, but not murine $\mathrm{C} 3$, bound to the cutaneous BMZ (Fig. $3 E$ ).

Histological studies of the skin of animals injected with pathogenic rabbit IgG. The skin changes seen in neonatal mice injected with pathogenic rabbit anti-murine BP180 IgG appear to be dependent on the activity of the complement system of the host animal. In animals with intact complement, i.e., the C5sufficient mouse strain, B10-D2-NSN and PBS-treated BALB/c mice, the histologic findings in the skin were similar to those previously reported when testing rabbit anti-BP180 IgG in normal neonatal BALB/c mice (18). There were zones of subepidermal vesicle formation, the majority of which were noninflammatory. In focal areas there were scattered neutrophils close to the dermal surface, and associated with some lesions there were collections of neutrophils located within the blister cavity. In contrast, passive transfer of rabbit anti-BP180 IgG into complement-deficient mice, (i.e., the C5-deficient strain or BALB/ 


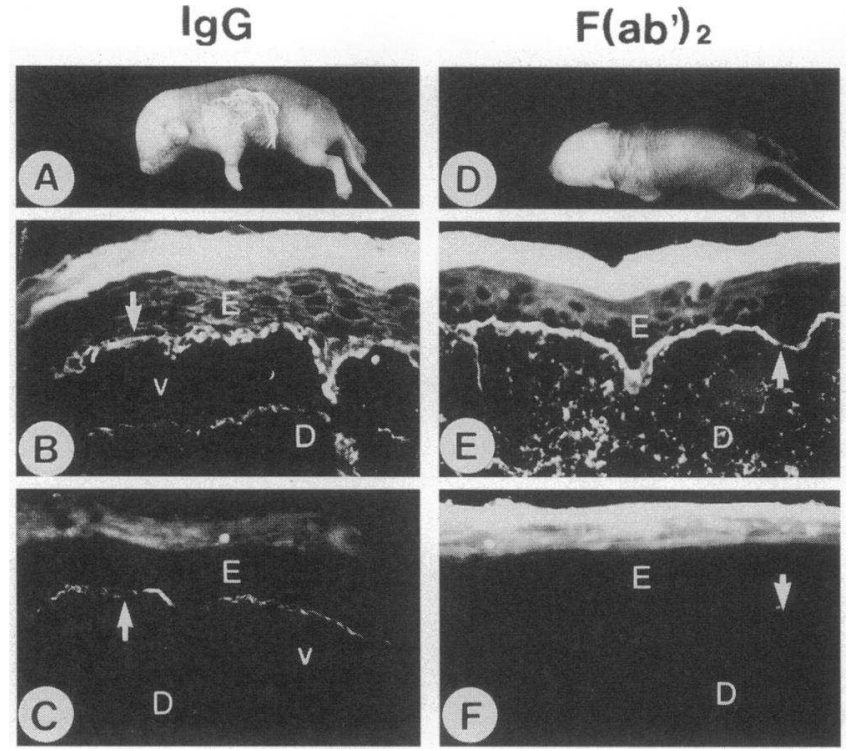

Figure 3. Clinical and immunofluorescence analysis of neonatal mice injected with the $\mathrm{F}\left(\mathrm{ab}^{\prime}\right)_{2}$ fragments of rabbit anti-murine BP180 IgG. The control group of neonatal BALB/c mice injected with intact rabbit anti-murine IgG developed extensive blisters $(A)$. These blisters were determined to be subepidermal by histologic examination and showed deposition of rabbit $\operatorname{IgG}(B)$ and murine $\mathrm{C} 3(C)$ along the BMZ of perilesional skin. In contrast, the skin of neonatal BALB/c mice that received injections of $F\left(a b^{\prime}\right)_{2}$ fragments of the same rabbit IgG showed no signs of skin disease, at either the clinical $(D)$ or histological levels (not shown). Direct IF studies of the skin of the $\mathrm{F}\left(\mathrm{ab}^{\prime}\right)_{2}$-injected mice showed strong binding of the rabbit $\mathrm{F}\left(\mathrm{ab}^{\prime}\right)_{2}$ fragments to the $\mathrm{BMZ}(E)$, but an absence of murine $\mathrm{C} 3(F)$. Site of antibody labeling (arrow), dermis $(D)$, epidermis $(E)$, vesicle $(V)(\times 400)$.

c mice pre-treated with CVF) produced very minimal or no inflammatory changes with no vesicle formation in the skin of the treated animals. Similarly, mice injected with rabbit $\mathrm{F}\left(\mathrm{ab}^{\prime}\right)_{2}$ fragments (that lack the complement-fixing Fc domain) exhibited hardly any inflammatory changes with no evidence of vesiculation. These findings are demonstrated in Fig. 4 (also see Table I).

\section{Discussion}

The present investigation was aimed at defining the role of complement activation on the pathogenesis of blister formation induced by the passive transfer of rabbit anti-murine BP180 IgG into neonatal BALB/c mice (18). We tested the effect of complement depletion in the host animal (using either a genetically C5-deficient mouse strain or BALB/c mice pretreated with CVF) in modulating the skin injury produced by pathogenic rabbit anti-BP180 antibodies. Additionally, we tested the effects of $\mathrm{F}\left(\mathrm{ab}^{\prime}\right)_{2}$ fragments generated from the pathogenic rabbit IgG in the generation of skin lesions in these animals. The results of these studies provide strong evidence supporting the notion that complement activation is essential for the production of subepidermal blisters induced by antiBP180 antibodies.

In one set of experiments a C5-deficient strain of mice (B10D2-OSN) and the syngeneic C5-sufficient strain (B10-D2NSN) were used as recipients of the rabbit anti-murine BP180

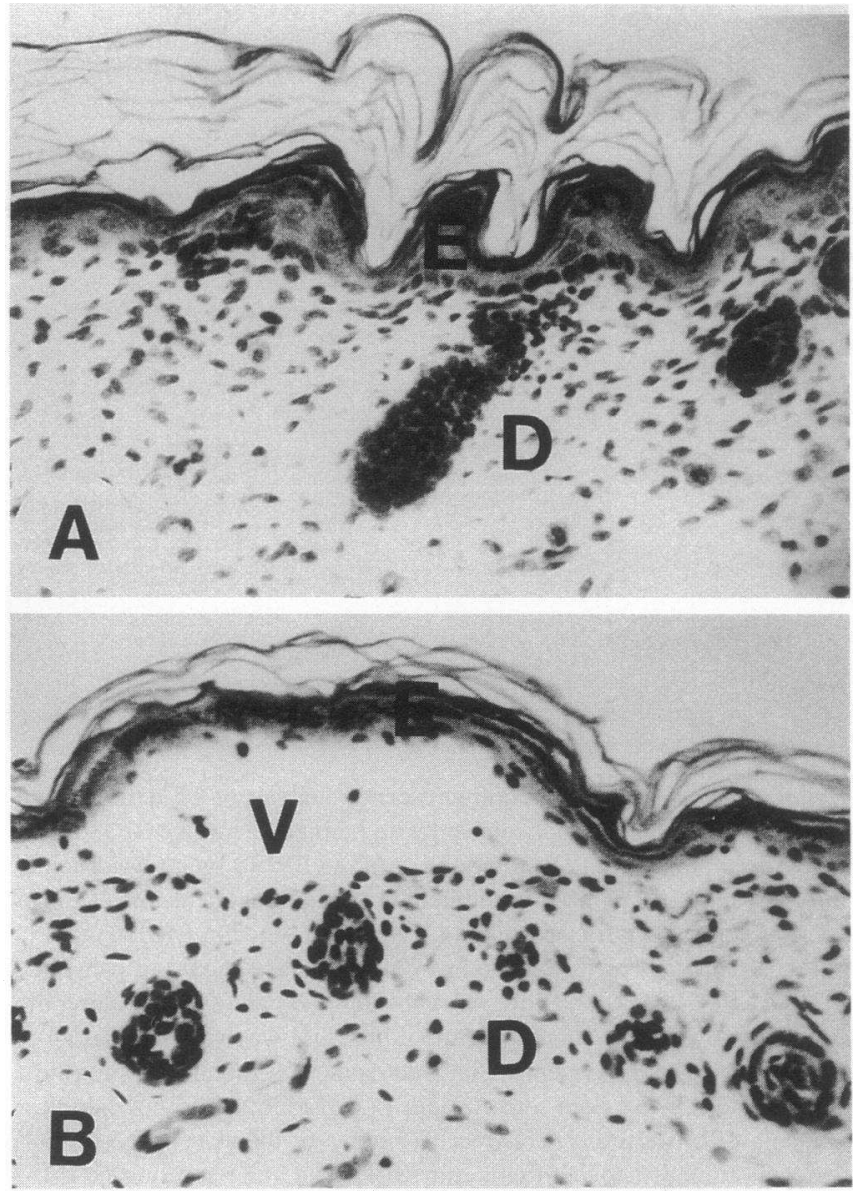

Figure 4. Histological examination of the skin of C5-sufficient and C5deficient mice injected intraperitoneally with pathogenic rabbit antimurine BP180 IgG. (A) Hematoxylin and Eosin-stained section from C5-deficient mouse showing no epidermal-dermal separation and little inflammation. ( $B$ ) Hematoxylin and Eosin-stained section from C5sufficient mouse showing a subepidermal vesicle $(V)$ with neutrophilic infiltrate. Epidermis $(E)$; dermis $(D)(\times 400)$.

IgG. We demonstrated that both strains of mice exhibited high titers of rabbit anti-murine BP180 antibodies in their sera, and both rabbit IgG and murine C3 were found to be bound to the cutaneous BMZ of these animals. However, subepidermal blistering and neutrophilic dermal infiltration were seen only in the C5-sufficient mouse strain. The C5-deficient mice showed no clinical or histological evidence of skin disease. These results indicated that activation of the components of the complement system ( $\mathrm{C} 5$ or later components) are required for the generation of skin lesions induced by rabbit anti-BP180 antibodies.

To further investigate the involvement of complement in subepidermal blister formation, BALB/c mice were depleted of complement by pretreatment with CVF (27) before receiving i.p. injections of pathogenic rabbit anti-BP180 IgG. Interestingly, mice pretreated with CVF became resistant to the pathogenic effects of the anti-BP180 antibodies-this, despite the fact that rabbit anti-BP180 antibodies reached high titers in the circulation of these mice and were efficiently deposited at the cutaneous BMZ. As expected, murine $\mathrm{C} 3$ was neither detected in the serum of these CVF-treated animals nor bound to the BMZ of their skin. Neutrophilic infiltration of the dermis of 
these mice was minimal or absent. These results further substantiate the important role of complement activation in mediating blister formation in the murine model of BP/HG.

Finally, since antibody-specific activation of the complement system is known to be mediated via the Fc portion of the IgG molecule, we tested whether removal of the Fc domain from the rabbit anti-BP180 IgG had any significant effect on the pathogenicity of this immunoglobulin. Divalent $\mathrm{F}\left(\mathrm{ab}^{\prime}\right)_{2}$ fragments were prepared from pathogenic rabbit anti-BP180 IgG and introduced i.p. into neonatal mice. $16 \mathrm{~h}$ after injection these mice exhibited circulating and tissue-bound $F\left(a b^{\prime}\right)_{2}$ in a manner identical with that of control mice that were injected with anti-BP180 IgG. However, in contrast with the control mice that additionally showed $\mathrm{C} 3$ deposition at the BMZ, neutrophilic infiltration and extensive subepidermal blistering disease, the mice injected with $F\left(a^{\prime}\right)_{2}$ showed none of these clinical, histological, or immunological changes. These findings indicate that the Fc portion of the pathogenic rabbit IgG is crucial in mediating epidermal injury in the mouse BP model. Since antigen-bound $F\left(a b^{\prime}\right)_{2}$ has been shown to activate $C$ through the alternative pathway (28), our results suggest that anti-BP180 IgG antibodies trigger subepidermal vesiculation via activation of the classical pathway of the complement system.

Although little is known about the exact mechanism of subepidermal blister formation in BP and HG patients, several studies have suggested that binding of BP autoantibodies to the cutaneous BMZ may be followed by complement activation, which in turn leads to inflammatory injury and subepidermal blister formation. These studies have shown the following. (a) BP and HG autoantibodies avidly fix complement in vitro (29, $30)$; ( $b$ ) $\mathrm{C} 3$ is detected by direct IF along the BMZ of perilesional skin in almost all cases of BP and HG, (4-6); (c) Both BP autoantibodies and C3 are detected by immuno-electron microscopy at the site of immunological injury, i.e., the lamina lucida of the skin $(31)$; $(d)$ components of both the classical and alternative pathways of complement (including $\mathrm{Clq}, \mathrm{C} 4$, C5, C5-9, factor B, B1H globulin, and properdin) have been detected in lesional skin of BP patients $(32) ;(e)$ levels of total hemolytic complement and of individual complement components in blister fluid from BP patients have been found to be lower than those detected in control blister fluids and in the sera of these patients $(33) ;(f)$ eosinophil-derived granules have been detected in BP blister fluid (34); $(g)$ eosinophils at BP lesional sites secrete $92-\mathrm{kD}$ gelatinase which is able to cleave in vitro the extracellular domain of recombinant BP180 antigen (35); $(h)$ blister fluid from BP patients contain chemotactic factors for neutrophils (36); and $(i)$ incubation of human skin cryosections with a BP serum plus complement and neutrophils resulted in the accumulation of neutrophils at the $\mathrm{BMZ}$ and subsequent microscopic separation at the dermal-epidermal junction (37). All three components-circulating autoantibodies, complement, and neutrophils - were found to be necessary for blister formation.

Clinical, histological and immunological analyses of the mouse model of BP/HG (presented here and in previous reports) appear to duplicate the key immunopathological findings in BP and HG patients (18). It is likely, therefore, that these human diseases, like the anti-BP180-induced experimental model, are triggered by local antibody-mediated activation of the complement system and induction of a secondary inflammatory injury to the cutaneous $\mathrm{BMZ}$ as postulated by Jordon et al. (38) and Sams and Gammon (39). The end result would be the formation of subepidermal blisters, the hallmark lesion of BP and HG. The mouse model of BP/HG should greatly facilitate future studies aimed at dissecting the role of inflammatory cells (such as neutrophils, mast cells and eosinophils) or inflammatory mediators in the molecular pathogenesis of blister formation in these autoimmune diseases.

\section{Acknowledgments}

This work was supported in part by U. S. Public Health Service Grants RO1-AR32599, R37-AR32081 (L. A. Diaz), R29-AR40410 (G. J. Giudice) and training grant T32-AR07577 from the National Institutes of Health and a VA Merit Grant (L. A. Diaz) awarded by the Veterans Administration Central Office.

\section{References}

1. Lever, W. F. 1953. Pemphigus. Medicine. 32:1-123.

2. Shornick, J. K., J. L. Bangert, R. G. Freeman, and J. N. Gilliam. 1983. Herpes gestationis: Clinical and histological features of twenty-eight cases. $J$. Am. Acad. 8:214-224.

3. Jordon, R. E., E. H. Beutner, E. Witebsky, G. Blumental, W. C. Hale, and W. F. Lever. 1967. Basement zone antibodies in bullous pemphigoid. J.A.M.A. 200:751-758.

4. Provost, T. T., and T. B. Tomasi, Jr. 1973. Evidence for complement activation via the alternative pathway in skin diseases. I. Herpes gestationis, systemic lupus erythematosus and bullous pemphigoid. J. Clin. Invest. 52:17791787.

5. Jordon, R. E., K. G. Heine, G. Tappeiner, L. L. Bushkell, and T. T. Provost. 1976. The immunopathology of herpes gestationis. Immunofluorescent studies and characterization of the "HG factor." J. Clin. Invest. 57:1426-1433.

6. Katz, S. I., K. C. Hertz, and H. Yaoita. 1976. Herpes gestationis. Immunopathology and characterization of the HG factor. J. Clin. Invest. 57:1434-1441.

7. Labib, R. S., G. J. Anhalt, H. P. Patel, D. F. Mutasim, and L. A. Diaz. 1986. Molecular heterogeneity of bullous pemphigoid antigens as detected by immunoblotting. J. Immunol. 136:1231-1235.

8. Morrison, L. H., R. S. Labib, J. J. Zone, L. A. Diaz, and G. J. Anhalt. 1988. Herpes gestationis autoantibodies recognize a $180-\mathrm{kD}$ human epidermal antigen. J. Clin. Invest. 81:2023-2026.

9. Stanley, J. R., T. Tanaka, S. Mueller, V. Klaus-Kovtun, and D. Roop. 1988. Isolation of a complementary DNA for bullous pemphigoid antigen by use of patients' autoantibodies. J. Clin. Invest. 82:1864-1870.

10. Diaz, L. A., H. Ratrie III, W. S. Saunders, S. Futamura, H. L. Squiquera, G. J. Anhalt, and G. J. Giudice. 1990. Isolation of a human epidermal cDNA corresponding to the $180-\mathrm{kD}$ autoantigen recognized by bullous pemphigoid and herpes gestationis sera. Immunolocalization of this protein to the hemidesmosome. J. Clin. Invest. 86:1088-1094.

11. Mutasim, D. F., Y. Takahashi, R. S. Labib, G. J. Anhalt, H. P. Patel, and L. A. Diaz. 1985. A pool of bullous pemphigoid antigen(s) is intracellular and associated with the basal cell cytoskeleton-hemidesmosome complex. J. Invest. Dermatol. 84:47-53.

12. Tanaka, T., N. J. Korman, H. Shimizu, A. J. Eady, V. Klaus-Kovtun, K. Cehrs, and J. R. Stanley. 1990. Production of rabbit antibodies against carboxyterminal epitopes encoded by bullous pemphigoid cDNA. J. Invest. Dermatol. 94:617-623.

13. Giudice, G. J., D. J. Emery, and L. A. Diaz. 1992. Cloning and primary structural analysis of the bullous pemphigoid autoantigen, BP-180. J. Invest. Dermatol. 99:243-250.

14. Hopkinson, S. B., K. S. Riddelle, and J. C. R. Jones. 1992. Cytoplasmic domain of the $180-\mathrm{kD}$ bullous pemphigoid antigen, a hemidesmosomal component: molecular and cell biologic characterization. J. Invest. Dermatol. 99:264270.

15. Giudice, G. J., H. L. Squiquera, P. M. Elias, and L. A. Diaz. 1991. Identification of two collagen domains within the bullous pemphigoid autoantigen, BP180. J. Clin. Invest. 87:734-738.

16. Nishikawa, Y., J. Uematsu, and K. Owaribe. 1993. HD4, a 180kDa bullous pemphigoid antigen, is a major transmembrane glycoprotein of the hemidesmosome. J. Biochem. 113:493-501.

17. Giudice, G. J., D. J. Emery, B. D. Zelickson, G. J. Anhalt, Z. Liu, and L. A. Diaz. 1993. Bullous Pemphigoid and Herpes Gestationis Autoantibodies Recognize a Common Non-collagenous Site on the BP180 Ectodomain. J. Immunol. 151:5742-5750.

18. Liu, Z., L. A. Diaz, J. L. Troy, A. F. Taylor, D. J. Emery, J. A. Fairley, and G. J. Giudice. 1993. A passive transfer model of the organ-specific autoim- 
mune disease, bullous pemphigoid, using antibodies generated against the hemidesmosomal antigen, BP180. J. Clin. Invest. 92:2480-2488.

19. Anhalt, G. J., R. S. Labib, J. J. Voorhees, T. F. Beals, and L. A. Diaz. 1982. Induction of pemphigus in mice by passive transfer of IgG from patients with the disease. N. Engl. J. Med. 306:1189-1196.

20. Roscoe, J. T., L. A. Diaz, S. A. P. Sampaio, R. M. Castro, R. S. Labib, H. Patel, and G. J. Anhalt. 1985. Brazilian pemphigus foliaceus autoantibodies are pathogenic to BALB/c mice by passive transfer. J. Invest. Dermatol. 85:538541 .

21. Anhalt, G. J., and L. A. Diaz. 1987. Animals models for bullous pemphigoid. Clin. Dermatol. 5:117-125.

22. Sams, W. M., Jr., and G. J. Gleich. 1971. Failure to transfer bullous pemphigoid with serum of patients. Proc. Soc. Exp. Biol. Med. 136:1027-1031.

23. Li, K., K. Tamai, E. M. L. Tan, and J. Uitto. 1993. Cloning of type XVII collagen. Complementary and genomic DNA sequences of mouse 180-Kilodalton bullous pemphigoid antigen (BPAG2) predict an interrupted collagenous domain, a transmembrane segment, and unusual features in the $5^{\prime}$-end of the gene and the 3 '-untranslated region of the mRNA. J. Biol. Chem. 268:8825-8834.

24. Liu, Z., L. A. Diaz, A. L. Haas, and G. J. Giudice. 1992. cDNA cloning of a novel human ubiquitin carrier protein. An antigenic domain specifically recognized by endemic pemphigus foliaceus autoantibodies is encoded in a secondary reading frame of this human epidermal transcript. J. Biol. Chem. 267:15829-15835.

25. Ballow, M., and C. G. Cochrane. 1969. Two anticomplementary factors in cobra venom: hemolysis of guinea pig erythrocytes by one of them. J. Immunol. 103:944-952.

26. Turner, M. W., H. H. Bennick, and J. B. Natvig. 1970. Simple method of subtyping human G-myeloma proteins based on sensitivity to pepsin digestion. Nature (Lond.). 225:853-855.

27. Pepys, M. B. 1975. Studies in vivo of cobra venom factor and murine C3. Immunology. 28:369-377.

28. Moore, F. D., D. T. Fearon, and K. F. Austen. 1981. IgG on mouse erythrocytes augments activation of the human alternative complement pathway by enhancing deposition of C3b. J. Immunol. 126:1805-1809.
29. Kelly, S. E., R. Cerio, B. S. Bhogal, and M. M. Black. 1989. The distribution of IgG subclasses in pemphigoid gestationis: PG Factor is an IgG1 autoantibody. J. Invest. Dermatol. 92:695-698.

30. Suzuki, M., S. Harada, and Y. Yaoita. 1992. Purification of bullous pemphigoid IgG subclasses and their capability for complement fixation. Acta. Derm. Venereol. (Stockh.) 72:245-249.

31. Schmidt-Ullich, B., A. Rule, G. Schaumburg-Lever, and C. Leblanc. 1975. Ultrastructural localization of in vivo-bound complement in bullous pemphigoid. J. Invest. Dermatol. 65:217-219.

32. Jordon, R. E., S. Kawana, and K. A. Fritz. 1985. Immunopathologic mechanisms in pemphigus and pemphigoid. J. Invest. Dermatol. 85:72s-78s.

33. Jordon, R. E., N. K. Day, W. M. Sam, Jr., and R. A. Good. 1973. The complement system in bullous pemphigoid. I. Complement and component levels in sera and blister fluids. J. Clin. Invest. 52:1207-1214.

34. Bara, T., H. Sonozaki, K. Seki, M. Uchiyama, Y. Ikesawa, and M. Torisu. 1976. An eosinophil chemotactic factor present in blister fluids of bullous pemphigoid patients. J. Immunol. 116:112-116.

35. Ståhle-Bäckdahl, M., M. Inoue, G. J. Giudice, and W. C. Parks. 1994. $92-$ $\mathrm{kD}$ gelatinase is produced by eosinophils at the site of blister formation in bullous pemphigoid and cleaces the extracellular domain of recombinant $180-\mathrm{kD}$ bullous pemphigoid autoantigen. J. Clin. Invest. 93:2022-2030.

36. Diaz-Perez, J. L., and R. E. Gordon. 1976. The complement system in bullous pemphigoid. IV. Chemotactic activity in blister fluid. Clin. Immunopathol. 5:360-370.

37. Gammon, W. R., C. C. Merritt, D. M. Lewis, W. M. Sams Jr., C. E. Wheeler, and J. Carlo. 1981. Leukocyte chemotaxis to the dermal-epiderma junction of human skin mediated by pemphigoid antibody and complement: Mechanism of cell attachment in the in vitro leukocyte attachment method. J. Invest. Dermatol. 76:514-522.

38. Jordon, R. E. 1975. Complement activation in bullous skin diseases. $J$. Invest. Dermatol. 65:162-169.

39. Sams, W. M., Jr., and W. R. Gammon. 1982. Mechanism of lesion production in pemphigus and pemphigoid. J. Am. Acad. Dermatol. 6:431-452. 